\title{
COMMENTARY
}

\section{Chimpanzees' Responses to the Dead Body of a 9-Year-Old Group Member}

\author{
EDWIN J.C. VAN LEEUWEN ${ }^{1,2,3 *}$, INNOCENT CHITALU MULENGA ${ }^{3}$, MARK D. BODAMER $^{3}$, \\ AND KATHERINE A. CRONIN ${ }^{4}$ \\ ${ }^{1}$ School of Psychology and Neuroscience, St. Andrews University, Scotland, United Kingdom \\ ${ }^{2}$ Max Planck Institute for Psycholinguistics, Nijmegen, The Netherlands \\ ${ }^{3}$ Chimfunshi Wildlife Orphanage Trust, Chingola, Zambia \\ ${ }^{4}$ Lester E. Fisher Center for the Study and Conservation of Apes, Lincoln Park Zoo, Chicago, Illinois
}

The social behavior of chimpanzees has been extensively studied, yet not much is known about how they behave in response to the death of a group member. Here, we provide a detailed report of the reactions of a group of chimpanzees to finding the dead body of a 9-year-old male group member. The behavior of the group was characterized by quiet attendance and close inspections punctuated by rare displays. Moreover, the body was continuously attended and closely inspected by several adults and juveniles, including an adult male who formed a close social bond with the deceased individual after the deceased individual's mother died 4 years earlier. When considered with observations of how chimpanzees respond to dead infants and adults in this group and in others, these observations suggest that chimpanzees' responses to death may be mediated by social bonds with the deceased individual. The results are discussed in light of recent reports on chimpanzees' reactions to dead community members and more general primate thanatology. Am. J. Primatol. 78:914-922, 2016. @ 2016 Wiley Periodicals, Inc.

Key words: social bonds; response to death; thanatology; Pan troglodytes; group processes

\section{INTRODUCTION}

There is growing interest in documenting and understanding how many primate species respond to death (prosimians, New World Monkeys, Old World Monkeys, and apes reviewed in Anderson [2011], see also Bezerra et al. [2014], Buhl et al. [2012], Fashing et al. [2011], Li et al. [2012]). Primates' behavioral responses toward deceased infants have predominated [e.g., Biro et al., 2010; Cronin et al., 2011; Hosaka et al., 2000; Kooriyama, 2009; Matsuzawa, 1997; Sugiyama et al., 2009; Watson et al., 2015]. In conjunction, these reports indicate that primate mothers often remain attached to the body of their deceased offspring in form of carrying around the body and protecting it from interactions with other group members. One study reported the repeated interactions of a chimpanzee mother with her deceased 16-month-old daughter in the transitional phase between constant care and separation [Cronin et al., 2011]. Among chimpanzees specifically, mothers seem to gradually allow conspecifics to approach the corpse and even condone manipulation of and playful interactions with the body [see Biro et al., 2010; Hosaka et al., 2000].

Chimpanzees are highly social animals. They live in social groups, spend a substantial amount of their time grooming and playing with each other and have the tendency to re-establish relationships after they have been compromised by aggression [e.g., de
Waal, 1998; Nishida et al., 1999; van LawickGoodall, 1968]. A paucity in our understanding of chimpanzees' sociality, however, exists with regard to their tendency to respond to the loss of group members. Where chimpanzees establish and actively maintain social bonds throughout life [e.g., Langergraber et al., 2009; Mitani, 2009], we know little about how these bonds might translate to behavior when confronted with death.

While reports on how chimpanzee mothers cope with the abrupt ending of the life of their infants provide valuable insights for our understanding of the mother-infant bond in chimpanzees, we know little about how the broader chimpanzee community responds to death, and specifically to the loss of a group member who is not an infant but rather has

Contract grant sponsor: Max Planck Institute for Psycholinguistics

*Correspondence to: Edwin J.C. van Leeuwen, School of Psychology and Neuroscience, St. Andrews University, St Mary Quad, South Street, KY16 9JP Scotland, UK.

E-mail: ejcvanleeuwen@gmail.com

Received 23 January 2016; revised 12 April 2016; revision accepted 13 April 2016

DOI: 10.1002/ajp.22560

Published online 9 May 2016 in Wiley Online Library

(wileyonlinelibrary.com). 
established social relationships with multiple others (hereafter "socially integrated" or "socially active"). Stewart et al. [2012] observed that the responses of the Gombe chimpanzees to the dead body of an adult female community member ranged from "curious observation and passive investigation (e.g., smelling and grooming) to the shaking, dragging, and frustrated beating of the body" [Stewart et al., 2012, p. 1]. More specifically, based on their observations, they proposed that the age of the "griever" should be incorporated in the quest to better understand what chimpanzees experience in response to death. They also noted that there is substantial individual and group-level variation in chimpanzees' death responses, as their report differed substantially from an earlier account of different Gombe chimpanzees who refrained from touching a dead body [Teleki, 1973]. Anderson et al. [2010] reported a case of a group response to "the peaceful demise of an elderly female" (p. 349), a process characterized by "several behaviors that recall human responses to the death of a close relative" (p. 349). Only by aggregating careful descriptions of primates' behavioral responses when confronted with naturally occurring deaths will we ultimately move toward an understanding of how non-human primates process death and uniquely advance our understanding of primate sociality [Anderson, 2011; Cronin et al., 2011].

Following is a detailed report of the reactions of a group of chimpanzees to finding the dead body of one of the group's socially active members: a 9-year-old adolescent male ("Thomas"). The observations start when the dead body is encountered by the chimpanzee caretakers and presumably also by the other chimpanzees. The behaviors of the chimpanzees in the area where the body was found are reported and subsequently compared to their behaviors toward two chimpanzee infants that had died previously in the same community and compared with reports from other communities in order to shed light on group responses toward the death of an active social member of a chimpanzee group.

\section{METHODS}

\section{Study Site and Subjects}

Observations were conducted at Chimfunshi Wildlife Orphanage Trust (Chimfunshi), a chimpanzee sanctuary accredited by the Pan African Sanctuary Alliance (PASA) in the Copperbelt region of Northwestern Zambia located approximately $60 \mathrm{~km}$ west of Chingola on the southern bank of the Kafue River. Many of the chimpanzees at Chimfunshi were rescued from illegal trade in Zambia between 1983 and 2004 and brought to Chimfunshi for rehabilitation and socialization. This report focuses on "Group 2 ," a group comprised of 43 individuals (3 adult males, 17 adult females, 7 juvenile males, 10 juvenile females, 6 infants) at the time of this report. In Group 2 specifically, $65 \%$ of the population was born in the group (35\% thus being wild-born), and the group had been closed to the introduction of newly rescued individuals for over 10 years prior to the event (for additional demographic details see Cronin et al., [2014]).

Group 2 lives outdoors in densely vegetated Miombo forest suitable for chimpanzees [Ron \& McGrew, 1988]. All enclosures have indoor holding areas used for mid-day feeding and visual health inspections, solar-powered electric fencing around the perimeter, and one observation deck. Group 2 inhabits a $0.65 \mathrm{~km}^{2}$ (160 acre) enclosure. Chimpanzees are provisioned in or near the indoor holding area from 11:30 AM until 1:30 PM; the whole group is in their forested enclosures at all other times of the day and overnight. Given the large size of the enclosure, it is not uncommon for the chimpanzees to be out of sight for researchers located at the fence or observation deck.

The deceased individual, Thomas (male), was born at the sanctuary on February 15, 2001 to TamTam, a wild-born chimpanzee who entered the sanctuary in July 1994 at approximately 7 years of age after confiscation from an Egyptian Circus. TamTam died in late 2006 when Thomas was 5 years old. In general, Thomas was characterized as a highly social individual, which was reflected in his tendency to frequently roam between sub-parties in the enclosure and remain near the entrance of the feeding building, where he, together with Pan (adult male), would vocalize or physically engage (greeting, playing, provoking) with passing conspecifics, mostly the adult females (Staff reports, pers. comm. 2007-2010).

Thomas was noted as missing from the mid-day feeding on May 16, 2010. Post-mortem inspection revealed that Thomas probably died from the combination of a viral and bacterial infection, causing severe impairments in breathing. The veterinarian was unable to determine how recently the death had occurred but the body was rigid upon removal from the enclosure. No injuries were found on his body.

\section{Data Collection and Coding}

On May 18, 2010, after 2 days of absence during mid-day feeding, Thomas' dead body was found by one of the chimpanzee caretakers (JK) approximately $3 \mathrm{~m}$ from the fence line (see Fig. 1 for orientation of body). The body had not been present in this location in the preceding hours, thus it appeared that one of the chimpanzees had recently dragged the body to this visible location (also given that the body was already stiff when it was removed from the enclosure roughly half and hour after finding it). Upon immediate signaling of JK, researcher EJC rushed to the location, arriving 


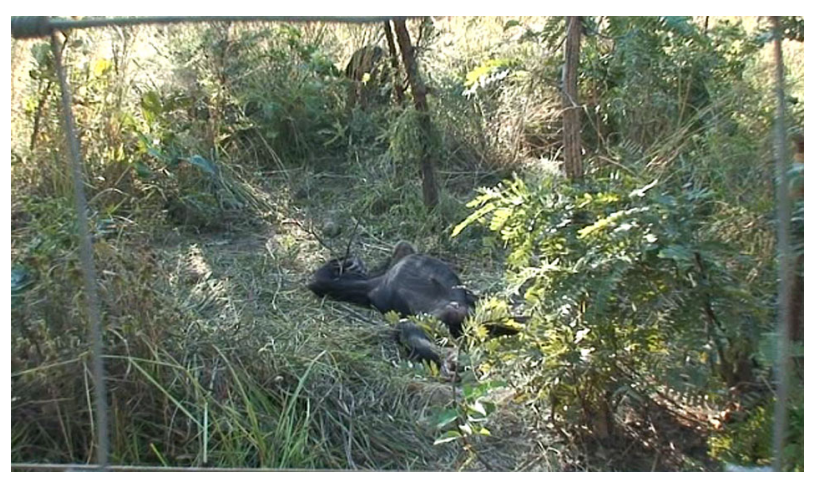

Fig. 1. Body lies approximately $3 \mathrm{~m}$ from the fence line from where the observations were made.

approximately $30 \mathrm{sec}$ after JK. Upon arrival, EJC started video recording the scene immediately (Supplementary Video 1). KAC (Supplementary Video 2) arrived 3 min later.

The scene was subsequently recorded uninterrupted for $20 \mathrm{~min}$ (Supplementary Video 1). EJC recorded with a Canon miniDV camera, approximately $1.5 \mathrm{~m}$ from KAC, who recorded with a Sony HD Handycam. Data collection adhered with PASA guidelines as well as the American Society of Primatologists Principles for the Ethical Treatment of Non-Human Primates.

Videos were synchronized for simultaneous dual views using ELAN 3.9 [Chebotko et al., 2004]. Behavior was coded using the ethogram in Table I. Thomas' dead body was treated as a passive focal subject, where proximity to the body and behaviors toward the body were coded for all chimpanzees within a radius of $3 \mathrm{~m}$ (reliable view) using scan sampling every $30 \mathrm{sec}$ [Martin \& Bateson, 2007]. For

TABLE I. Ethogram of the Behaviors Scored During the Observations Around Thomas' Body

\begin{tabular}{|c|c|}
\hline Behavior & Description \\
\hline Rest & $\begin{array}{l}\text { Individual is sleeping, standing, or sitting but } \\
\text { not actively playing, grooming, or engaging in } \\
\text { any social behavior. Eyes may be open or } \\
\text { closed. Not vocalizing. }\end{array}$ \\
\hline Peer & $\begin{array}{l}\text { Individual moves within a distance of less than } \\
\text { half of the length of one chimpanzee arm } \\
(\sim 35 \mathrm{~cm}) \text { and orients their head toward the } \\
\text { dead body without physically engaging. }\end{array}$ \\
\hline Inspect & $\begin{array}{l}\text { Manual or other physical inspection of any } \\
\text { region of the dead body (does include } \\
\text { grooming, with and without objects). }\end{array}$ \\
\hline Move & $\begin{array}{l}\text { Individual changes location by at least one body } \\
\text { length by walking, running, crawling, or } \\
\text { climbing. }\end{array}$ \\
\hline Hit & $\begin{array}{l}\text { Making physical contact with the body by means } \\
\text { of a rapid movement with one or two arms. }\end{array}$ \\
\hline
\end{tabular}

behavioral coding, we did not include physical contact with the body other than "inspection" and "hit," for in many instances this would have been difficult to code reliably due to the obstructed view from several individuals surrounding the body. Proximity data were coded conservatively with $0.5 \mathrm{~m}$ increments (range 0.5-3.0 from the body; distances less than 0.5 were coded as 0.5). In addition, all displays involving the body and one extended grooming event (teeth cleaning) are reported in detail.

\section{RESULTS}

\section{Presence and Proximity of Group Members to Thomas' Body}

At the start of the data collection, two chimpanzees (Pippa: adult female, and Vis: juvenile male) were present near Thomas' body. The proportional presence of the group around Thomas' body throughout the observation window is presented in Figure 2. Given the large size of the enclosure of Group 2 $\left(0.65 \mathrm{~km}^{2}\right)$ and the natural tendency of chimpanzees to organize themselves in fission-fusion communities [Stanford, 1998], we do not know to what extent all group members were aware of the death and location of Thomas at the time of video recording. Therefore, all the presented data are relative to the total number of individuals that were observed (and hence assumed to be knowledgeable of the location of the body) at least once within a radius of $3 \mathrm{~m}$ of the body ( $N=28,65 \%$ of the group) throughout the entire observation window (thus likely making for a conservative estimate of the proportion of individuals present at Thomas' body). The average percent of the knowledgeable group present at the location of the body over the 20-min period was $42.8 \%$ (SD $=23.1$ ). Just prior to 3.5 and $17 \mathrm{~min}$, a display by Pan and Violet (the alpha female), respectively scattered the group from the body (see below for detailed descriptions). After $17 \mathrm{~min}$, the chimpanzee caretakers started their attempt to lure the chimpanzees away from the body ( $17 \mathrm{~min} 21 \mathrm{sec}$, Supplementary Video 1), in order to be able to safely remove the body from the enclosure. Excluding the data of 3.5 and 17.5-20 min, the average percentage of the knowledgeable group present at the location of the body was $48.5 \%(\mathrm{SD}=20.7)$.

The average proximity of the chimpanzees to the body throughout the observation window was $0.92 \mathrm{~m}$ $(\mathrm{SD}=0.57)$. Since space is limited within the $1 \mathrm{~m}$ diameter around the body, we also report the median and IQR for proximity to the body (both $0.5 \mathrm{~m}$ ). Excluding the data of 3.5 and $17.5-20 \mathrm{~min}$, the proximity measures representing chimpanzees' closeness to the body remained exactly the same $(X \pm \mathrm{SD}=0.92 \pm 0.57 \mathrm{~m}$, Median and $\mathrm{IQR}=0.5 \mathrm{~m})$. Notably, immediately following the two displays 


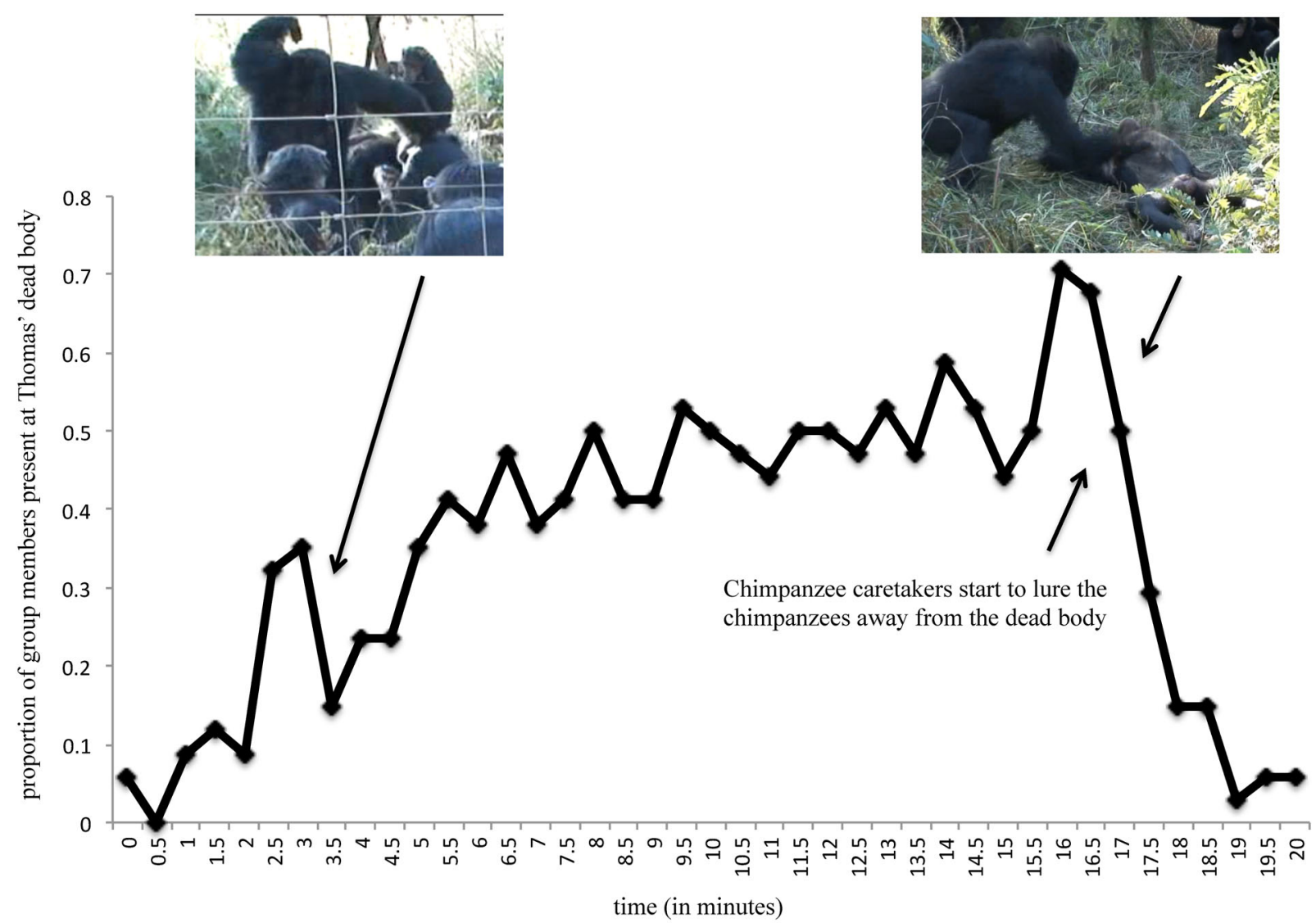

Fig. 2. Proportional presence of group members at Thomas' body. Indicated with photos and arrows are the two displays that occurred close to the body, the first by Pan (adult male) and the second by Violet (adult female).

described below, the average proximity of the chimpanzees differed by more than two standard deviations from the overall average proximity (both $1.3 \mathrm{~m}$ ), indicating that the displays temporarily distanced others from the body.

\section{Behaviors of the Group Members in Proximity to Thomas' Body}

The behaviors of the group members who were present at Thomas' body (within $3 \mathrm{~m}$ ) are presented together with frequencies in Figure 3. We observed individuals peering (watching the body closely from within $35 \mathrm{~cm}$, see ethogram), inspecting, and hitting the body, yet most frequently, the group members sat quietly around the body (resting: $72.6 \%$ of scored behaviors; see Fig. 4a), while occasionally one or more individuals would physically inspect the body (5.1\% of scored behaviors; see Fig. 4b). In total, at least 9 individuals physically interacted with the body at least once, while at least 22 individuals peered at the body at least once (see Fig. 3). Videos in the supplementary data show the full time course of events (Supplementary Videos 1 and 2).

\section{Displays}

During the observation period, two individuals displayed over Thomas' body: Pan (adult male) and Violet (adult female).

\section{Pan Displays Over Thomas' Body}

At $2 \mathrm{~m} 09$, two adult females and their offspring (Masya and Diana) were being followed on their way to the body, where at least four individuals had gathered already (2m13). An unknown individual started vocalizing, and several individuals subsequently joined. Between $2 \mathrm{~m} 12$ and $2 \mathrm{~m} 20$, at least two adult females (Violet and Diana) touched the body, then Pan (2m20) and Zsabu (2m24; alpha male) arrived. Between $2 \mathrm{~m} 25$ and $2 \mathrm{~m} 28$, Pan displaced an adult female (presumably Pippa) who appeared to touch Thomas' body. Over the next $20 \mathrm{sec}$, several adult females peered at the body, as did Pan and Zsabu. Zsabu and Pan left the scene a few seconds before Noel touched the body between $2 \mathrm{~m} 58$ and $3 \mathrm{~m} 09$ and subsequently brought her hand to her lips. Pan returned at $3 \mathrm{~m} 17$, when he approached Noel, approximately $3 \mathrm{~m}$ from body. Together with Violet, Pan peered at Noel, where he held his face close 


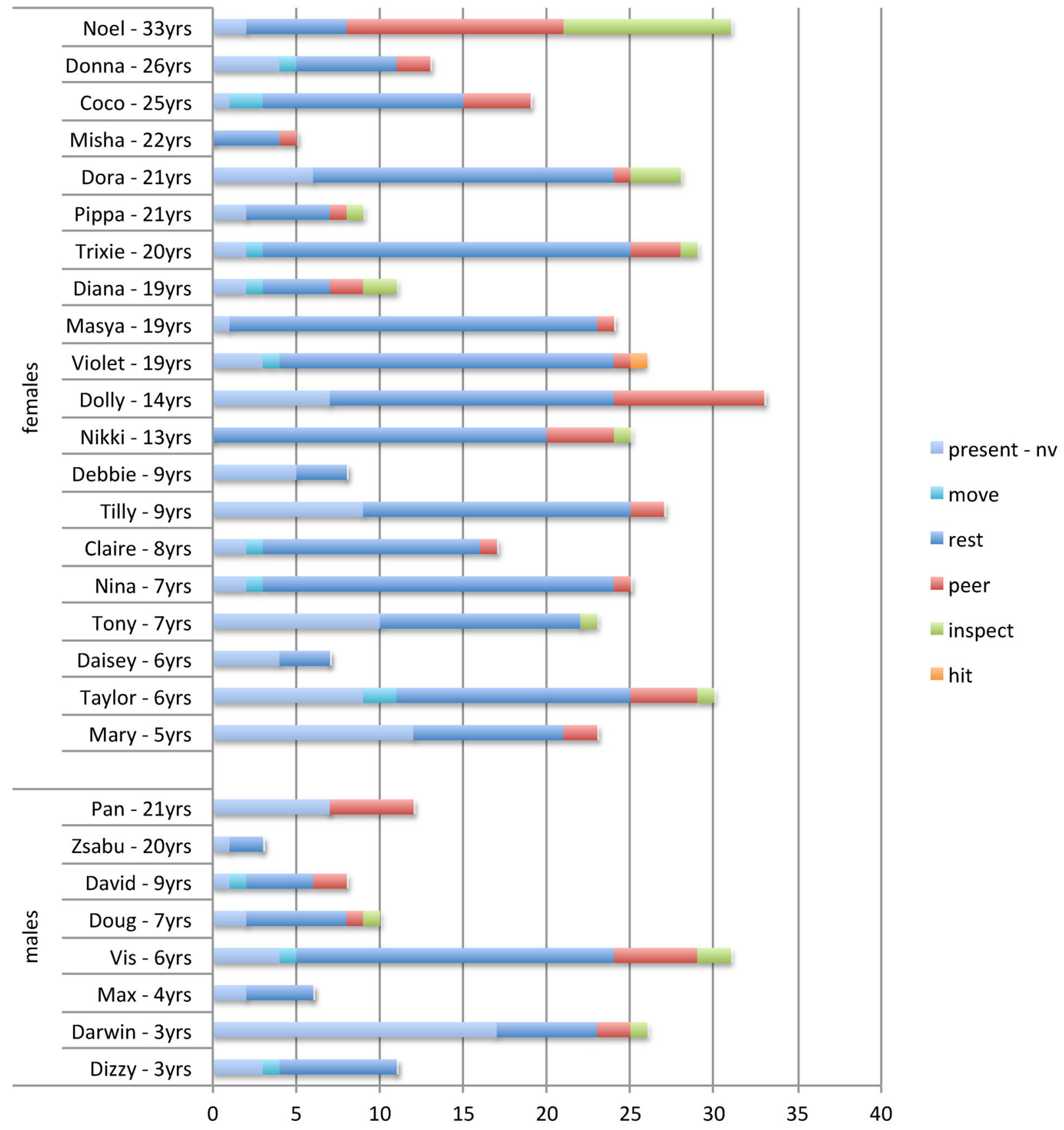

Fig. 3. Number of 30-sec intervals in which individuals were observed to engage in moving around, resting, peering, inspecting, and hitting the body. Data shown for all individuals who were present within $3 \mathrm{~m}$ of the body at some point during the observation period. "Present - nv" indicates that individuals were present but obscured to an extent that the exact behavior was impossible to score. In total, 41 scans were made; during the last 6 scans, the chimpanzee caretakers worked on luring the chimpanzees away from Thomas' body in order to be able to remove the body from the enclosure.

(within $10 \mathrm{~cm}$ ) to Noel's face for 1 sec. Subsequently, Pan departed Noel bipedally in the direction of the body, where at least 12 individuals had gathered within $3 \mathrm{~m}$ of the body. Immediately following, Pan grabbed a branch and lunged with high speed over the body. In response to Pan's lunge, the gathered individuals scattered, and at least four individuals screamed. At 3m20-3m22, Pan lunged past the left side of the body, piloerect, with both arms raised, then hits an unidentified female or the ground near her. The respective female immediately started chasing Pan, during which they both disappear from the scene.

After his display, Pan forced access to the body by pushing through others on three separate occasions, then peered closely and inspected the 

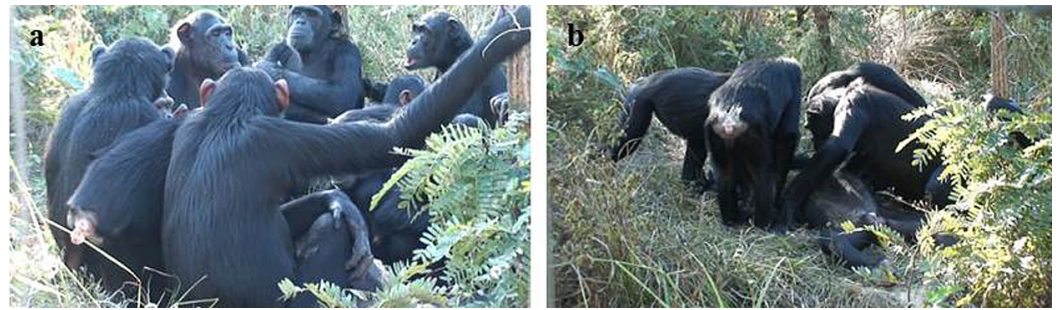

Fig. 4. Example behavioral responses at the location of Thomas' dead body, where (a) adult females gather around the body and (b) adult females and juveniles inspect the body.

body (at $6 \mathrm{~m} 21-6 \mathrm{~m} 51,9 \mathrm{~m} 57-10 \mathrm{~m} 54$, and $16 \mathrm{~m} 46$ $17 \mathrm{~m} 18)$. Moreover, between $18 \mathrm{~m} 35$ and $18 \mathrm{~m} 40$, Pan arrived at Thomas' body running and mildly displaying again (pulling branches twice, shortly chasing a female once), after which he left the scene again at $18 \mathrm{~m} 42$ (still running). While not being counted present within a $3-\mathrm{m}$ radius of the body, Pan was captured on video approximately $6 \mathrm{~m}$ southwest of the body three more times during infrequent video scans that occurred at $11 \mathrm{~m} 20$, $12 \mathrm{~m} 53$, and $13 \mathrm{~m} 19$ (see Supplementary Video 2).

\section{Violet Displays Over Thomas' Body}

At $17 \mathrm{~m} 0$, Violet sat down $1 \mathrm{~m}$ north of the body, while holding on to a branch with her left arm. From $17 \mathrm{~m} 0$ to $17 \mathrm{~m} 10$, she watched the body, while at least 16 individuals were present within a radius of $3 \mathrm{~m}$. At $17 \mathrm{~m} 11$, Violet, together with Trixie (adult female) and Nikkie (adolescent female), started looking west toward the food building located approximately $30 \mathrm{~m}$ away where chimpanzee caretakers had gathered to start luring the chimpanzees away from the body. At $17 \mathrm{~m} 18$, Pan left the scene; Violet watched him leave. At $17 \mathrm{~m} 20$, one of the females began to pant hoot. At $17 \mathrm{~m} 21$, the chimpanzee caretakers started calling the chimpanzees toward the food building, which coincided with at least four individuals at the body vocalizing with increasing intensity $(17 \mathrm{~m} 21-17 \mathrm{~m} 30)$. Between
$17 \mathrm{~m} 24$ and $17 \mathrm{~m} 30$, Violet built up her scream while standing bipedally and holding on to the same branch as before with her left arm. During this display, Violet swayed back and forth while intensifying her scream and slowly getting closer to the body. At $17 \mathrm{~m} 30$, Violet released the branch and hit the body hard with her right arm. After hitting the body, Violet immediately lunged away from the body, leaving the scene running northwest, where she halted approximately $3.5 \mathrm{~m}$ from the body at $17 \mathrm{~m} 33$. From $17 \mathrm{~m} 33$ to $17 \mathrm{~m} 39$, Violet stood quadrupedally with her back toward the body, after which she started moving further northwest until she was out of sight at $17 \mathrm{~m} 42$.

\section{Teeth Cleaning}

We describe in some detail one additional behavior directed to Thomas' body, given the persistence with which the female performed it.

Following the display by Violet, who hit Thomas' body at $17 \mathrm{~m} 30$ (see above), several individuals returned to the body to within $0.5 \mathrm{~m}$ at $17 \mathrm{~m} 35$ $17 \mathrm{~m} 37$ (adult females: Coco, Dora, and Noel; juveniles: Darwin, on the back of Dora and Taylor). Nikkie and Trixie had remained in proximity to Thomas' body throughout Violet's display. At 18m01, Noel started inspecting Thomas' face with her mouth and hands. She paused briefly while caretakers were calling the chimpanzees toward the feeding building,
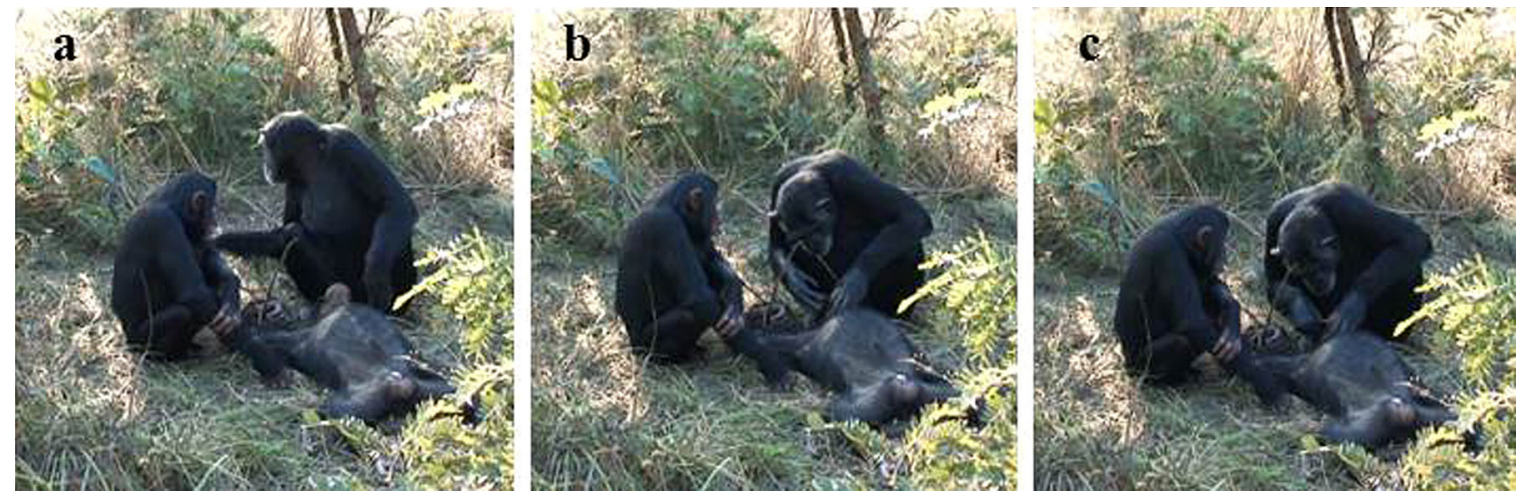

Fig. 5. One of the adult females (Noel) (a) selects a grass stem, (b) holds the grass in her mouth while inspecting Thomas' mouth with her hands, and (c) subsequently uses the grass stem to pick at Thomas' teeth. 
but at $18 \mathrm{~m} 29$ Noel resumed inspecting Thomas' face. At $19 \mathrm{~m} 17$, Noel picked a piece of grass, put it in her mouth, and started to inspect Thomas' face with her hands. At 19m21, Noel took the grass from her mouth and used it to clean Thomas' teeth. At $19 \mathrm{~m} 47$, Noel raised her hands, touched the end of the grass stem with her free hand, put the hand that touched the grass stem in her mouth and did the same with the grass stem. Between 19m59 and 20m08, Noel resumed cleaning Thomas' teeth with her grass stem, regularly putting the grass stem in her own mouth as well. Nina (Noel's daughter) was the only other chimpanzee present. When the recording ended at $20 \mathrm{~m} 08$, Noel and Nina were still within $0.5 \mathrm{~m}$ of Thomas body while Noel cleaned Thomas' teeth with a grass stem and Nina watched (see Fig. 5).

\section{DISCUSSION}

Reported here are the behavioral responses of a group of chimpanzees after finding the dead body of an active social group member, a 9-year-old male. The observations occurred during a unique window where most chimpanzees presumably arrived at the body for the first time and could behave freely in their natural environment for approximately $20 \mathrm{~min}$, after which the chimpanzee caretakers started the process of removing the body from the enclosure. While reports on the behavioral responses of primate mothers toward their deceased offspring have accumulated over time allowing for an interesting insight into the strength of primate mother-infant bonds and flexible nature of their response, little is known about how chimpanzees respond to the death of older, presumably more integrated members of the social group.

Our observations show that more than half of all group members approached Thomas' body at least once and that close to half of the group members remained in close proximity to his body for the full observation period. These behavioral responses are strikingly different from the group responses to the death of a chimpanzee infant in the same group, where only one adult female (Noel) other than the mother (Masya) spent time in close proximity to the dead body, and only three juveniles and four adults (three females) briefly interacted with the body [see Cronin et al., 2011]. When another chimpanzee infant from the same group died 1 year later, the behavioral responses of the group were even less pronounced, as the mother let other individuals (primarily two juveniles) play with the dying infant before the moment of death. Similar to the first case of infant death, there was no prolonged group attendance in close proximity to the body (while there was ample opportunity for it), nor any close inspections by group members other than the mother [Cronin et al. unpublished data]. These opportunistically observed group processes indicate that chimpanzees' responses to the death of group members may be mediated by age, and the social integration or social history of the deceased. Interestingly, anthropological accounts of early human societies similarly indicate that while the death of an infant remains largely insignificant, the death of an active, adult group member triggers the society into an elaborate state of grievance and rituals [Hertz, 1960]. While more observations are obviously needed, these findings indicate that social animals may share the tendency to respond to the death of socially active group members collectively, while socially less active group members may be only attended to by close relatives [see Anderson et al., 2010; Cronin et al., 2011; Hertz, 1960].

It is difficult to assess the impact of the chimpanzees' captive environment on their responses to finding a dead group member. While wild chimpanzees may have more space to roam, the chimpanzees of this particular group in Chimfunshi have sufficient space available to disperse in sub-groups typical of their fission-fusion form of subsistence [Ron \& McGrew, 1988; Stanford, 1998]. However, it is plausible that because these chimpanzees are provided supplementary food every day in a set location that brings the group into proximity, members of the group may have discovered the body sooner than they would have if they were more dispersed in the wild. The specific behavioral patterns described in this report - the resting party around the body, the adult male's behavior, the teeth cleaning - are not easily interpreted by referring to the chimpanzees' captive environment. Lastly, to consider differences between chimpanzees' responses to the death of infants versus integrated members of the society, the report compares the focal observations to the chimpanzees' behavior during another death encounter in the same group [Cronin et al., 2011], thereby "controlling" for any kind of behavioral artifact induced by the captive environment.

The behavior of Pan supports the hypothesis that social bonds may influence chimpanzee responses to the death of group mates. Staff reports from 2007 to 2010 indicate that after TamTam died, Thomas continuously stayed close to Pan while foraging and sleeping, both outdoors and inside the holding building (where space is limited), and received support from Pan during agonistic encounters. Pan was one of only two individuals to display near the body and, unlike Violet, he refrained from physically contacting the body during his displays. The observation that Pan visited and inspected Thomas' body more than any other adult male may reflect the strong social connection they shared in life. The fact that chimpanzee males adopt and take care of (unrelated) infants and juveniles in the wild [see Boesch et al., 2010] and form long-term social bonds [Mitani, 2009], at least allows for this interpretation to be considered. Alternatively, the display behaviors could be interpreted more in line with the potential 
Chimpanzee Group's Response to Death / 921

function of the chimpanzees' physical inspections of the body: learning about their close surroundings, in this case "death" [Cronin et al., 2011; Hosaka et al., 2000]. By engaging in behaviors that would normally elicit clear behavioral responses, both Pan and Violet could have acquired reliable information on the status of Thomas' body (see also the increased investigatory reactions of the other chimpanzees after Violet's display). Clearly, an interaction between these two alternatives would also be possible, where the individuals that were socially most connected with Thomas throughout life could be most motivated to gather information about his current state.

We additionally report that the adult female, Noel, inspected and cleaned Thomas' teeth with extensive care (Supplementary Videos; also see Fig. 5). Thomas appeared to have shared a close relationship with Noel. Staff reports indicate that the relationship between Thomas and Noel was established prior to TamTam's (Thomas' mother) death, as Noel and her offspring (Nina and Nikkie) spent a substantial amount of time in close proximity to TamTam and Thomas, including while feeding. Noel, Nikkie, and Nina engaged in grooming and playing behavior with Thomas regularly (Staff reports, pers. comm. 2010). Cleaning and inspecting another's teeth has been reported between live chimpanzees [see Mcgrew \& Tutin, 1973]. This was the most prolonged and detailed behavior directed toward the body, and the fact that it was performed by an individual who shared a close social relationship with Thomas further supports the hypothesis that chimpanzees may respond differently to the death of group members based on their previous social relationships. Moreover, teeth cleaning of a recently deceased individual could arguably be seen as a "compassionate" behavior, adding to the previous description of captive chimpanzees' responses to the death of a group member [Anderson et al., 2010] and supporting the claim that within the non-human primate order perhaps chimpanzees respond to the death of group members with relatively marked empathetic care (also see Fashing et al. [2011], but see Bezerra et al. [2014]). Clearly, however, more observations are needed to verify this claim.

The frequency of "resting," or quiet, calm sitting in close proximity to one another was striking considering the high level of excitement often shown by chimpanzees when large groups are attracted to interesting or novel "commodities." Interestingly, similar quiet attendance was reported for the Tai forest chimpanzees in response to the death of a 10year-old juvenile [Pettitt, 2011], and for the Gombe National Park chimpanzees (Kasekela community) in response to the death of a 20-year-old (estimated) female [Stewart et al., 2012], and has been designated as one of the main characteristics of (early) human mourning responses [Davies \& Rumble, 2012].

Teleki [1973] proposed that the Gombe chimpanzees might have responded differently to the death of a group member based on their social relationship with the deceased, and that does seem to explain the group response in the current report. While we lack the systematic data collection prior to Thomas' death that would allow us to statistically determine whether those with close social bonds were more likely than others to attend to and interact with the body, the extensive keeper reports and our own observations of the chimpanzee relationships prior to Thomas' death suggest that the interest in the body was not random but related to prior social relationships. These observations suggest that in non-human primates as in humans, close relationships mitigate individual differences in behavioral responses to death.

\section{ACKNOWLEDGMENTS}

The authors thank the Zambia Wildlife Authority for granting us permission to study chimpanzees in Zambia and the Chimfunshi founders Sheila and (the late) David Siddle for their ongoing support of Chimfunshi and the Chimfunshi Board of Trustees. A special thank you (twatotela) to the staff whose chimpanzee expertise was integral to this report: Patrick Chambatu, Felix Chinyama, John Kayuya, Joseph Kasongo, Albert Mulembo, and Patrick Mwika. We also thank Nick Wood and the Technical Group of the Max Planck Institute for Psycholinguistics.

\section{REFERENCES}

Anderson JR. 2011. A primatological perspective on death. American Journal of Primatology 73:410-414.

Anderson JR, Gillies A, Lock LC. 2010. Pan thanatology. Current Biology 20:R349-R351.

Bezerra BM, Keasey MP, Schiel N, da Silva Souto A. 2014. Responses towards a dying adult group member in a wild New World monkey. Primates 55:185-188.

Biro D, Humle T, Koops K, et al. 2010. Chimpanzee mothers at Bossou, Guinea carry the mummified remains of their dead infants. Current Biology 20:R351-R352.

Boesch C, Bole C, Eckhardt N, Boesch H. 2010. Altruism in forest chimpanzees: the case of adoption. PLoS ONE 5: e8901. doi:10.1371/journal.pone.0008901

Buhl JS, Aure B, Ruiz-Lambides A, et al. 2012. Response of rhesus macaques (Macaca mulatta) to the body of a group member that died from a fatal attack. International Journal of Primatology 33:860-871.

Chebotko A, Yu D, Lu S, et al. 2004. OntoELAN: an ontologybased linguistic multimedia annotator. Proceedings. IEEE Sixth International Symposium on Multimedia Software.

Cronin KA, van Leeuwen EJC, Mulenga IC, Bodamer MD. 2011. Behavioral response of a chimpanzee mother toward her dead Infant. American Journal of Primatology 73:415-421.

Cronin KA, van Leeuwen EJC, Vreeman V, Haun DBM. 2014. Population-level variability in the social climates of four chimpanzee societies. Evolution and Human Behavior 35:389-396. 
Davies D, Rumble H. 2012. Natural burial: traditional-secular spiritualities and funeral innovation. London: Continuum.

de Waal F. 1998. Chimpanzee politics: power and sex among apes. Revised edition. Baltimore, Maryland: The Johns Hopkins University Press.

Fashing PJ, Nguyen N, Barry TS, et al. 2011. Death among geladas (Theropithecus gelada): a broader perspective on mummified infants and primate thanatology. American Journal of Primatology 73:405-409.

Hertz R. 1960. A contribution to the study of the collective representation of death. In: Needham R, Needham C, editors. Death and the right hand. New York: Free Press. p 27-86.

Hosaka K, Matsumoto-Oda A, Huffman MA, Kawanaka K. 2000. Reactions to dead bodies of conspecifics by wild chimpanzees in the Mahale Mountaina, Tanzania. Primate Research 16:1-15.

Kooriyama T. 2009. The death of a newborn chimpanzee at Mahale: reactions of its mother and other individuals to the body. Pan Africa News 16:19-21.

Langergraber K, Mitani J, Vigilant L. 2009. Kinship and social bonds in female chimpanzees (Pan troglodytes). American Journal of Primatology 71:840-851.

Li T, Ren B, Li D, Zhang Y, Li M. 2012. Maternal responses to dead infants in Yunnan snub-nosed monkey (Rhinopithecus bieti) in the Baimaxueshan Nature Reserve, Yunnan, China. Primates 53:127-132.

Martin P, Bateson P. 2007. Measuring behaviour: an introductory guide. Cambridge: Cambridge University Press.

Matsuzawa T. 1997. The death of an infant chimpanzee at Bossou, Guinea. Pan Africa News 4:4-6.

Mcgrew WC, Tutin CEG. 1973. Chimpanzee tool use in dental grooming. Nature 241:477-478.

Mitani JC. 2009. Male chimpanzees form enduring and equitable social bonds. Animal Behaviour 77:633640 .
Nishida T, Kano T, Goodall J, McGrew WC, Nakamura M. 1999. Ethogram and ethnography of Mahale chimpanzees. Anthropological Science 107:141-188.

Pettitt P. 2011. The palaeolithic origins of human burial. London: Routledge.

Ron T, McGrew WC. 1988. Ecological assessment for a chimpanzee rehabilitation project in Northern Zambia. Primate Conservation 9:37-41.

Stanford CB. 1998. The social behavior of chimpanzees and bonobos-empirical evidence and shifting assumptions. Current Anthropology 39:399-420.

Stewart FA, Piel AK, O'Malley RC. 2012. Responses of chimpanzees to a recently dead community member at Gombe National Park, Tanzania. American Journal of Primatology 74:1-7.

Sugiyama Y, Kurita H, Matsui T, Kimoto S, Shimomura T. 2009. Carrying of dead infants by Japanese macaque (Macaca fuscata) mothers. Anthropological Science 117: 113-119.

Teleki G. 1973. Group response to accidental death of a chimpanzee in Gombe-National-Park, Tanzania. Folia Primatologica 20:81-94.

van Lawick-Goodall J. 1968. The behaviour of free-living chimpanzees in the Gombe Stream Reserve. Animal Behaviour Monographs 1:161-311.

Watson C, Hashimoto N, Takayoshi N, Okamoto M, Matsuzawa T. 2015. Two cases of dead-infant carrying followed by mother-infant cannibalism in captive socially housed Japanese macaques. Folia Primatologica 86:378-379.

\section{SUPPORTING INFORMATION}

Additional supporting information may be found in the online version of this article at the publisher's web-site. 